\title{
Zirconia: the material of choice in implant dentistry? an update
}

\begin{abstract}
Although titanium is actually still the main material of choice to produce dental implants, there seems to be nowadays an obvious trend to fabricate these implants from more biocompatible materials. For the latter zirconia shows excellent conditions. Moreover, zirconia offers the dentist also the advantage to work with a more aesthetic solution. Although zirconia is already used in medicine for decades, there is still a lack of peerreviewed research on the use of this material in dental implantology.
\end{abstract}

Volume 6 Issue 6 - 2017

\author{
Curd Bollen 1,2 \\ 'Department of Periodontology Halitosis Implantology, Oral \\ Clinical Center, Netherlands \\ 2Parimplant Research Group, Netherlands
}

\begin{abstract}
Correspondence: Curd Bollen, Department of Periodontology Halitosis Implantology, Oral Clinical Center, Eyckholtstraat I-6I I6 BR Roosteren, Netherlands, Tel 00-3165366-6824,Email dr.curdbollen@gmail.com
\end{abstract}

Received: March 03, 2017 | Published: March 31, 2017

\section{Introduction}

In a recent survey in Europe of over 250 people, by the Swiss implant company Straumann; most patients seem to prefer a ceramic implant (35\%) over a titanium implant (10\%), whereas still more than $50 \%$ had no specific preference. Presently however, the implant market is still largely dominated by titanium implants $(>95 \%)$ and therefore ceramic implants are actually not more than a niche product. But as amalgam fillings were replaced by composites over the years, "white can become the new grey" as implant material. ${ }^{1}$ But times are changing since established implant companies are manufacturing now their own ceramic implant-line: e.g. Straumann ${ }^{\circledR}$ (Pure Ceramic), Camlog ${ }^{\circledR}$ (Ceralog), Medentis ${ }^{\circledR}$ (ICX-white) and Bredent ${ }^{\circledR}$ (whiteSKY). For clinicians the ceramic implant solution is a valuable opportunity to expand their patient base, especially in challenging esthetic cases, moreover in patients with a thin gingiva type. Also the group of patients demanding for metal-free or bio-holistic implant treatments is increasing constantly. Whereas in the past the used ceramic materials were often of an "inferior" quality, the actual zirconia implants are at least as reliable as their titanium counterparts. But still, ceramic implants carry a questionable reputation, nevertheless the growing amount of peer-reviewed scientific publications. This update clarifies the actual situation.

\section{History}

Zirconium was discovered by the German chemist M.H. Klaproth in 1789. He also discovered uranium (1789) and cerium (1803). He described them as distinct elements, though he did not obtain them in the pure metallic state. Zirconium $(\mathrm{Zr})$ is the chemical element with atomic number 40 . The name is taken from mineral zircon, the most important source of zirconium. It is a strong, grayish-white, transition metal that resembles hafnium and titanium. It is, just as titanium and hafnium, part of the group of transition metals. Zirconium forms inorganic (zirconium dioxide) and organometallic (zirconocene dichloride) compounds. Five isotopes occur naturally, three of which are stable. Zirconium dioxide is called zirconia, which is often used in aerospace or as cutting tool in the watch industry. ${ }^{2}$ This zirconia has outstanding mechanical properties, such as a high resistance to scratching and to corrosion. It is a stable product and is highly biocompatible. Three different crystalline phases are determined: a monoclinic phase, a cubic phase and a tetragonal phase. The latter is the one that is clinically used. Yttrium, the chemical element with symbol Y and atomic number 39 (a silvery-metallic transition metal chemically similar to the lanthanides and often been classified as a "rare earth element), is added for aging resistance and so the Yttria Tetragonal Zirconia Polycristal (YTZP) is formed. This is a bioinert material with high mechanical properties: it is 6 times harder than stainless steel!

Moreover YTZP has some other eloquent characteristics:

a. Electrical neutral.

b. Low thermal conductivity.

c. High resistance to high temperature.

d. High thermal shock resistance.

e. Chemical stability.

Due to all these criteria, zirconia is an excellent material for medical and dental applications.

\section{Titanium vs zirconia}

Straumann ${ }^{\circledR}$ made an internal comparison between their SLAtitanium implant and their ZLA-zirconia implant. ${ }^{3}$ The data showed clearly better characteristics for the zirconia implants (Table 1). Zirconia is highly biocompatible since it releases no ions and it creates an excellent osteoblast attachment and cellular proliferation which is responsible for a rapid growth of the bone-implant interface. ${ }^{4,5}$ These characteristics are in contrast with titanium that compromises cell viability and induces apoptosis, leading to a reduction of viable osteoblasts and a reduction of the bone quality. ${ }^{6}$ Moreover, in comparison to titanium, zirconia showed no induction of any adverse reaction or global toxic effect in vitro. Tests were performed on fibroblasts, lymphocytes, monocytes, macrophages, connective tissues, immunologic and bone tissues (Table 2). ${ }^{7,8}$ 
Table I Comparison characteristics Ti grade IV and YTZP

\begin{tabular}{lll}
\hline & Ti Grade I & YTZP \\
\hline Density & $4,5 \mathrm{~g} / \mathrm{cm}^{3}$ & $6,05 \mathrm{~g} / \mathrm{cm}^{3}$ \\
Hardness & $250 \mathrm{HV}$ & $1100-1500 \mathrm{HV}$ \\
Strength & $680 \mathrm{MPa}$ & $1200 \mathrm{MPa}$ \\
Elasticity & $110 \mathrm{GPa}$ & $200-220 \mathrm{GPa}$ \\
\hline
\end{tabular}

Table 2 Biological comparison titanium versus zirconia

\begin{tabular}{lll}
\hline & Titanium & Zirconia \\
\hline lon release & Yes & No \\
Toxicity & Low & No \\
Plaque adhesion & Low & Very low \\
\hline
\end{tabular}

When plaque adhesion was studied into more detail, only cocci and some short rods were found on zirconia surfaces. Motile microorganisms were not detected. ${ }^{9}$ It was also found that the early adhesion and colonization of bacteria on zirconia surfaces was much less than on titanium surfaces. These characteristics lead to a clear favorable soft tissue healing around zirconia. ${ }^{10}$ Since titanium can cause a nonspecific immunomodulation, it induces autoimmunity, leading to a demonstrated sensitization to titanium. ${ }^{11}$ The latter is not detected in zirconia. Studies show no difference in the initial osseo-integration between titanium and zirconia. But when searching the literature, it is obvious that there is a lack of long-term studies involving zirconia implants. ${ }^{12}$ When the perio-integration is evaluated, it is clear that there is a better fibroblast adhesion on zirconia, leading to a stronger cuff around the implants. This results in shallower sulcus depths with a mostly inflammation free environment. ${ }^{13,14}$

\section{Aging and radioactivity}

At room temperature, zirconia is retained in a metastable tetragonal phase by the addition of stabilizing agents (e.g. yttria); the aging of zirconia consists in a return towards the more stable monoclinic phase. This transformation occurs preferentially at the surface of tetragonal zirconia ceramics. It has been shown that the tetragonal to monoclinic $(\mathrm{t}-\mathrm{m})$ transformation at the surface of zirconia ceramics is promoted by the presence of water molecules in the environment. Being subject to a volume increase, this $t-m$ transformation induces the formation of microcracks at the surface, and an increase of the roughness. Microcracking leads to a decrease of the mechanical properties. ${ }^{15,16}$ This phenomenon is less applicable on the new generations of zirconia. Zirconia implants are slightly radioactive. Whereas a femoral head of nearly $100 \mathrm{~g}$ deliver $0,5 \mathrm{mSv} /$ year, a dental implant $(2 \mathrm{~g})$ is responsible for a dose of $0,01 \mathrm{mSv} /$ year. In comparison, the average normal yearly exposure is $2,4 \mathrm{mSv} /$ year, so this seems negligible. ${ }^{17}$

\section{Aesthetics}

As titanium can present a grey shadow trough the gums or in case of gingival retraction (accelerated by the release of toxic titanium particles), zirconia has proven its aesthetic superiority in implant dentistry. Most of the zirconia implants come in an A2 color. Therefore they have an irrefutable advantage in patients with a thin biotype. ${ }^{18}$

\section{Surface roughness and surface free energy}

In the early nineties Quirynen and Bollen stated that $0,2 \mu \mathrm{m}$ is the threshold surface roughness for microbial adhesion: a lower surface roughness has no extra impact on the bacterial accumulation on the surface, whereas a higher surface roughness is clearly connected to more plaque adhesion. ${ }^{19} \mathrm{~A}$ lot of recent studies focus on the surface roughness of zirconia in the oral cavity. When the surface roughness of crowns is considered, the different finishing protocols determine the final roughness: ${ }^{20,21}$

a. Glazed surface: $0,42-0,76 \mu \mathrm{m}$.

b. Surface finished with diamond burs: $0,89 \mu \mathrm{m}$.

c. Surface finished with diamond burs and then polished: $0,49 \mu \mathrm{m}$.

d. Only polished zirconia: $0,17 \mu \mathrm{m}$.

The surface roughness of zirconia abutments is situated between 0,2 and $0,3 \mu \mathrm{m} .{ }^{22}$ For implants there is difference between the body part $(1,2-1,6 \mu \mathrm{m})$ and the collar $(0,3 \mu \mathrm{m})$. The smooth collar prevents the plaque adhesion and stimulates the perio-integration, whereas the rougher surface of the body is favoring the osseo-integration. ${ }^{23}$ The surface free energy of titanium is much higher than the surface free energy of zirconia, provoking more bacterial adhesion. ${ }^{24}$

\section{The market}

There are several international players in the zirconia dental implant market. But only a limited number of these companies can offer peer-reviewed research on their products. Mostly there are only some in vitro studies or case presentations available

Z-systems ${ }^{\circledR}$ (PubMed - 5 publications: 2006-2016): Implants from Z-Systems ${ }^{\circledR}$ are made with the Zirkolith ${ }^{\circledR}$ process which as key advantages:

i. The breaking strength depends on the manufacturing process. Zirkolith ${ }^{\circledR}$ ceramic implants are carefully made in several steps and then post-processed, offering a high breaking strength.

ii. The SLM ${ }^{\circledR}$ surface which has been developed and patented by Z-Systems ${ }^{\circledR}$ achieves a surface enlargement through increased macro and micro roughness. This leads to improved bone integration. Healing with the latest generation of Zirkolith ${ }^{\circledR}$ ceramics is over $98 \%$, which is comparable to leading titanium implants.

iii. Zirkolith ${ }^{\circledR}$ ceramic implants are plasma sterilized, which is more gentle to the material.

iv. Zirkolith ${ }^{\circledR}$ ceramic implants can be ground in the mouth as with a natural tooth.

A clinical study by Blaschke and Volz shows that Z-system ${ }^{\circledR}$ implants are a feasible alternative to titanium dental implants. In addition to excellent cosmetic results, zirconia implants allow a degree of perio-integration / soft tissue response that is superior to titanium dental implants. ${ }^{25}$

Straumann ${ }^{\circledR}$ (PubMed - 3 publications: 2012-2017): The Straumann ${ }^{\circledR}$ PURE Ceramic implant is a monotype design that consists of an implant and abutment made from zirconium-dioxide ceramic. The natural-looking ivory color makes the implant look more like a natural tooth and supports the clinician in cases of thin gingiva biotype or soft tissue recession. As part of Straumann's quality control measures: forces that exceed the maximum human bite capacity are applied. The Straumann ${ }^{\circledR}$ PURE Ceramic implant features a ZLA 
surface, which is based on the well-documented Straumann ${ }^{\circledR}$ SLA surface. The ZLA and SLA surfaces have very similar topographies. Published research data indicates a similar healing pattern, healing time of 6 to 12 weeks and bone maintenance for the ZLA and the SLA surface. The ZLA surface demonstrates fast and predictable osseointegration, which is beneficial in successful implant treatment. ${ }^{26}$

Swiss dental solutions- SDS ${ }^{\circledR}$ (PubMed - 1 publication: 2006): SDS ${ }^{\circledR}$ implants are made of the material TZP (tetragonal zirconia polycristal). The implants are provided with an optimized "SLAsimilar" surface (surface additively blasted with zirconia) and they have Dynamic Thread, which is tried and tested in all bone classes. The abutment can be ground deeply and then used as a standard abutment for cementing crown/bridge treatments, without additional work steps being required after direct impression. The two-piece implant system is based on over 15 years of experience in the development of ceramic implants. The load-bearing upper part of the implant and the implant abutment connection, have a very solid design. Its two-piece design allows for concealed healing along with high success rates, especially in the posterior region..$^{27}$

Ceraroot ${ }^{\circledR}$ (PubMed - 5 publications: 2007-2010): Ceraroot ${ }^{\circledR}$, with over 10 year's clinical follow-up, is the first ever zirconium implant with acid etched surface, providing an optimal macro-, micro- and nano-roughness: the ICE Surface ${ }^{\circledR}$. It is a rough surface specially designed for achieving faster and stronger osseo-integration compared to machined zirconium oxide implants. According to the long-term data that Ceraroot ${ }^{\circledR}$ has accumulated over the years, there seems to be no bone remodeling around Ceraroot $\AA$ implants in patients with good oral hygiene from clinical cases performed back in 2003. Ceraroot ${ }^{\circledR}$ implants also demonstrate to be designed properly, as there hasn't been any report of a patient fracturing the implant. ${ }^{28}$

Zeramex® (PubMed - 4 publications : 2015-2016): Zeramex ${ }^{\circledR}$ represents an aesthetic and metal-free all-ceramic implant system that addresses a growing patient need. After four years of intensive research, the company presented in 2009 a two-part implant system made of white high-performance ceramic, with strong evidence, particularly in regards to the aesthetics and safety of the implants. Due to the anchoring of a two-piece system, the implant is initially hidden and can heal in the jawbone. After this, the prosthetic structures, abutment and crown, are applied. The two-part design is also a requirement for a flexible restoration with a lot of freedom. The stability of zirconium oxide is similar to titanium: strength tests (ISO 14801) show the high break resistance and durability. ${ }^{29}$

\section{Future}

The dental implant market is continuously in evolution. An implant fitting the extraction socket could be the solution! At the present time there are over 250 implant companies, manufacturing over a thousand screw-type implants-yet not a single screw fits the tooth socket. BioImplant ${ }^{\circledR}$ is a dental implant specifically designed for immediate implantation. It is fundamentally different to screw-type implants, and cannot be compared with them in any way. The extracted root is scanned and milled in zirconia: exactly a copy of the lost root. The implant fits exactly into the tooth socket, and therefore any operation on hard or soft tissue, augmentation with cadaver/artificial bone, is absolutely unnecessary. Furthermore, only the periodontal ligament is removed, but never the bone. As there are no operations (the implant is tapped into the socket), there are no complicated guidelines to follow. Drilling guides, bone substitutes, membranes, and product-specific surgical sets and drilling sequences are not applicable. BioImplant ${ }^{\circledR}$ is a single-piece implant, customized in form and color to the patient's individual tooth, whether single or multi-rooted. The prefabricated crown stump can be adjusted at any time in the same way as a natural tooth. ${ }^{30}$ This interesting evolution in implant dentistry is maybe the necessary nudge to help changing implantology into a "white, metal free" discipline. ${ }^{31}$

\section{Acknowledgments}

None.

\section{Conflicts of interest}

The authors declare there is no conflict of interest.

\section{References}

1. Bollen CML. White or Grey? Ceramic or Metal?. EC Dental Science. 2016;28-29.

2. Radhakrishnan JK, Kamble SS, Krishnapur PP, et al. Zirconia Oxygen Sensor for aerospace applications. Sixth International Conference on Sensing Technology (ICST). 2012.

3. Official data by Straumann ${ }^{\circledR}$.

4. Depprich R, Zipprich H, Ommerborn M, et al. Osseointegration of zirconia implants compared with titanium: an in vivo study. Head Face Med. 2008;4:30.

5. Olmedo DG, Tasat D, Guglielmotti MB, et al. Titanium transport through the blood stream. An experimental study on rats. J Mater Sci Mater Med. 2003;14(12):1099-1103.

6. Bächle M, Butz F, Hübner U, et al. Behavior of CAL72 osteoblast-like cells cultured on zirconia ceramics with different surface topographies. Clin Oral Implants Res. 2007;18(1):53-59.

7. Uo M, Sjögren G, Sundh A, et al. Cytotoxicity and bonding property of dental ceramics. Dent Mater. 2003;19(6):487-492.

8. Blaschke C, Volz U. Soft and hard tissue response to zirconium dioxide dental implants--a clinical study in man. Neuro Endocrinol Lett. 2006;27 Supp1 1:69-72.

9. Bollen CM, Papaioanno W, Van Eldere J, et al. The influence of abutment surface roughness on plaque accumulation and peri-implant mucositis. Clin Oral Implants Res. 1996;7(3):201-211.

10. Hisbergues M, Vendeville S, Vendeville P. Zirconia: Established facts and perspectives for a biomaterial in dental implantology. J Biomed Mater Res B Appl Biomater. 2009;88(2):519-529.

11. Stejskal J, Stejskal VD. The role of metals in autoimmunity and the link to neuroendocrinology. Neuro Endocrinol Lett. 1999;20(6):351-364.

12. Kohal RJ, Wolkewitz M, Hinze M, et al. Biomechanical and histological behavior of zirconia implants: an experiment in the rat. Clin Oral Implants Res. 2009;20(4):333-339.

13. Grössner Schreiber B, Herzog M, Hedderich J, et al. Focal adhesion contact formation by fibroblasts cultured on surface-modified dental implants: an in vitro study. Clin Oral Implants Res. 2006;17(6):736-745.

14. Degidi M, Artese L, Scarano A, et al. Inflammatory infiltrate, microvessel density, nitric oxide synthase expression, vascular endothelial growth factor expression, and proliferative activity in peri-implant soft tissues around titanium and zirconium oxide healing caps. J Periodontol. 2006;77(1):73-80.

15. Deville S. Low-temperature ageing of zirconia-toughened alumina ceramics and its implication in biomedical implants. Journal of the European Ceramic Society. 2003;23:2975-2982. 
16. Chevalier J, Loh J, Gremillard L, et al. Low-temperature degradation in zirconia with a porous surface. Acta Biomater. 2011;7(7):2986-2993.

17. Porstendörfer J, Reineking A, Willert HC. Radiation risk estimation based on activity measurements of zirconium oxide implants. J Biomed Mater Res. 1996;32(4):663-667.

18. Jung RE, Sailer I, Hämmerle $\mathrm{CH}$, et al. In vitro color changes of soft tissues caused by restorative materials. Int $J$ Periodontics Restorative Dent. 2007;27(3):251-257.

19. Quirynen M, Bollen CM. The influence of surface roughness and surfacefree energy on supra- and subgingival plaque formation in man. A review of the literature. J Clin Periodontol. 1995;22(1):1-14.

20. Sabrah AH, Cook NB, Luangruangrong P, et al. Full-contour Y-TZP ceramic surface roughness effect on synthetic hydroxyapatite wear. Dent Mater. 2013;29(6):666-673.

21. Janyavula S, Lawson N, Cakir D, et al. The wear of polished and glazed zirconia against enamel. J Prosthet Dent. 2013;109(1):22-29.

22. Van Brakel R, Meijer GJ, Verhoeven JW, et al. Soft tissue response to zirconia and titanium implant abutments: an in vivo within-subject comparison. J Clin Periodontol. 2012;39(10):995-1001.

23. Fischer J, Schott A, Märtin S. Surface micro-structuring of zirconia dental implants. Clin Oral Implants Res 2016;27(2):162-166.

24. Al-Haj Husain N, Özcan M. A Study on Topographical Properties and Surface Wettability of Monolithic Zirconia after Use of Diverse Polishing Instruments with Different Surface Coatings. J Prosthodont. 2016.
25. Hoffmann O, Angelov N, Zafiropoulos GG, et al. Osseointegration of zirconia implants with different surface characteristics: an evaluation in rabbits. Int J Oral Maxillofac Implants. 2012;27(2):352-358.

26. Bormann KH, Gellrich NC, Kniha H, et al. Biomechanical evaluation of a microstructured zirconia implant by a removal torque comparison with a standard Ti-SLA implant. Clin Oral Implants Res. 2012;23(10):1210 1216.

27. Blaschke C, Volz U. Soft and hard tissue response to zirconium dioxide dental implants-a clinical study in man. Neuro Endocrinol Lett D. 2006; Suppl 1:69-72.

28. Oliva J, Oliva X, Oliva JD. Five-year success rate of 831 consecutively placed Zirconia dental implants in humans: a comparison of three different rough surfaces. Int J Oral Maxillofac Implants. 2010;25(2):336-344.

29. Cionca N, Müller N, Mombelli A. Two-piece zirconia implants supporting all-ceramic crowns: a prospective clinical study. Clin Oral Implants Res. 2015;26(4):413-418.

30. Anssari Moin D, Hassan B, Wismeijer DA. Novel approach for custom three-dimensional printing of a zirconia root analogue implant by digital light processing. Clin Oral Implants Res. 2016;1-3.

31. Bollen CML. White is the new grey! Oral Health and Dentistry. 2016;1:1-3. 